Est Ag 45 (2010) 449-489

\title{
Estudio sobre el catecismo pictográfico de Alemania
}

Como pasa en tantas ocasiones, la casualidad, acompañada de la perseverancia, ponen en nuestro camino cosas que en otro momento no aparecieron, a pesar de ser buscadas.

Esto es lo que ha sucedido con este catecismo pictográfico, para mí desconocido, aunque sí tenía noticias de él. En efecto, la publicación de Glass, que hace un censo de catecismos pictográficos (aunque siempre haya que seguir actualizándolo), daba noticia de este pictográficoํ. Lo describe de esta forma:

«N 817

Deutsche Staatsbibliothek, Berlin, East Germany. American Manucript $n^{\circ} 1$ (part). Humboldt Fragment 16. Ex-Boturini, León y Gama, and Humboldt collections. Published. Native paper. 1 leaf. $35 \times 45 \mathrm{~cm}$.

The manuscript is distinguished from other Testerians by its size, native paper, the clustering of symbols, and variant style and symbols. The identifications of the paper fiber is discussed by Schwede (1916, pp. 52-54).

The manuscript was published, in color, by Humboldt (1810, p. 283, pl. 57). A b/w natural-size photoreproduction appears in Historische Hieroglyphen (1892). Seler (1893, pp. 116-123) gives a detailed commentary. An English translation of the commentary with an added reproduction of copy is given in Seler (1904f, pp. 221-223, pl. 21). A slight revision of the commentary (Seler, 1902e, pp. 289-299) lacks a full reproduction. See Humboldt Fragments in pictorial census (Article 23) for a general statement concerning the Humboldt collection.

Bibliography: Historische Hieroglyphen, 1892; Humboldt, 1810, Schwede, 1916; Seler, 1893, 1902e, 1904f».

A la anterior descripción hay que añadir que también está reproducido, simplemente como una muestra del estilo de los catecismos pictográficos, en

1 J. B. Glass, A census of Middle American Testerian Manuscripts, en Handbook of Middle American Indians, Austin (Texas), 14 (1975) 291-292. 
recto era la parte que estaba a la vista, mientras que el vuelto no interesaba para nada, porque estaba contra la pared, y carecía de sentido hacer dibujos en él. Sólo de esta manera se entienden su tamaño, la ausencia de dobleces (salvo el central), y la carencia de pictogramas en el vuelto de la hoja. Estamos, pues, ante un testimonio de que los murales pictográficos eran utilizados, como evidencian algunos gráficos en los que se muestra el uso de pinturas por parte de los misioneros en México; éstos empleaban tales cuadros para la explicación en la iglesia, y en las dependencias conventuales ${ }^{3}$.

La descripción de Glass, coincidente con la de la New Catholic Encyclopedia, señala que se trata de papel no europeo: «Native paper» o «agave paper» 4 . Cuando los españoles fueron conociendo México, descubrieron los manuscritos mexicanos, hechos sobre la base de esta fibra de pita o agave. Ellos preferían, en principio, el papel de factura europea, al que estaban acostumbrados y cuyo rendimiento y propiedades conocían; pero pronto, ante la abundancia de plantas y la lenta llegada de remesas de papel europeo, comenzaron a utilizar el papel de pita, como en este caso.

La hoja ha sido empleada, al menos en la cara que contiene los pictogramas, para este fin exclusivo, pues no hay trazas de que hubiera contenido otra información que hubiera sido borrada. Los pictogramas, han sido trazados con tinta negra, como está descrito, de forma que el conjunto es una composición en blanco y negro, no coloreado, que carece de la vistosidad de otros catecismos pictográficos en que se ha empleado el color; pero esto no le resta valor documental.

La hoja ha sido dividida en bandas, por medio de unas líneas horizontales trazadas a mano. Hay un total de ocho líneas, que enmarcan siete bandas. Las líneas primera y octava están casi en el límite del papel, con la intención clara de aprovecharlo al máximo. Como sucede en otras ocasiones, estas líneas, y las bandas correspondientes han sido trazadas antes de proceder a la serie de pictogramas, de manera que el amanuense o tlacuilo disponía ya del marco en que realizar su labor (como si de papel pautado se tratara). Las líneas horizontales que delimitan las bandas tienen un claro pa-

${ }^{3}$ D. VAladÉs, Rhetorica Christiana, Perusiae, Petrumiacobum Petrutium, 1579, 207 y 211. (Ed. a cargo de E. Palomera, México, Fondo de Cultura Económica, 1989).

${ }^{4} \mathrm{El}$ agave es planta de América meridional, de raíces fibrosas y de hojas carnosas, provistas de dientes terminados en espinas, que se insertan en un tallo muy corto que forman como una especie de roseta, baja, casi a ras de suelo; en el centro del tallo, brota, cuando la planta tiene 10 ó 12 años, una inflorescencia que alcanza varios metros de altura. Se la conoce también con el nombre de pita. Sus hojas sirven para la extracción de fibras, que son una importante materia textil. La anotación de Glass señala que «the identification of paper fiber is discussed by Schweden». 
ralelismo, y la altura de las bandas viene a ser, de promedio, de unos cinco centímetros, es decir, bastante grandes.

La segunda división es la que ha ido haciendo el tlacuilo a medida que dibujaba cada escena (según los casos contienen un número variable de pictogramas): trazaba una línea vertical, también a mano, desde la parte superior hasta la inferior de la banda, para separar una de otra. Es un procedimiento sencillo, que ha sido empleado en otros catecismos pictográficos, para delimitar los contenidos de lo que se presentaba, y que no apareciera como una continuidad sin orden alguno ${ }^{5}$. La separación con líneas verticales a lo largo de cada banda hace que ésta quede dividida en cuadros o escenas; la extensión de cada uno de ellos es variable, en función de lo que trataba de representar, y del número de pictogramas que hubiera de albergar. En este caso, están trazadas casi todas las líneas verticales, lo que muestra que el tlacuilo cometió pocas equivocaciones en ese punto. Faltan únicamente dos, que señalaré en su momento al describir al detalle el contenido del catecismo.

Tampoco hay tachaduras ni dibujos equivocados o dejados a medias. Es decir, hay una cierta soltura y dominio de lo que se pretendía hacer, aunque no hay maestría en los dibujos. Una vez concluido lo que había previsto dibujar, el espacio quedó en blanco: es lo que ocurre en la última banda, en la que están dibujadas sólo dos escenas (la primera de ellas deteriorada por un desgarro); entre las dos ocupan aproximadamente un $25 \%$ de la banda, y el $75 \%$ restante aparece en blanco, sin utilizar.

A pesar de esa cierta seguridad, los dibujos son en general toscos, desproporcionados, si bien los rasgos faciales de los personajes son muy acordes con las representaciones del mundo náhuatl. Por el contrario, las manos que dibuja tienen todos los dedos de la misma longitud y resultan poco precisas.

Se adivinan una serie de influencias europeas que aparecen más adelante al describir uno a uno los pictogramas: la figura del Espíritu Santo representada por un ave; la imagen del infierno al que bajó Cristo tras su muerte; la representación de la idea de humanidad, por medio de los atributos de la pasión (cruz, lanza y esponja); la tierra dibujada como la bola del mundo que Dios tiene en su mano; la presencia de unos personajes lampiños y otros barbudos. Por el contrario, no se aprecia esa influencia en la representación de la idea de padre, pues no recurre, como hacen otros catecismos, al dibujo de un religioso al que también se denominaba con ese apelativo; dibuja una persona con evi-

5 Así sucede, por ejemplo, en G334, o en G338, en el Catecismo atribuido a Pedro de Gante. Ver L. Resines, Catecismos pictográficos de Pedro de Gante, Incompleto y Mucagua, Madrid, Fundación Universitaria Española, 2007, 137-138. 
dentes rasgos indígenas. A la hora de dibujar a María, la madre de Jesús, no recurre al pictograma que emplea indistintamente para la idea de madre o de mujer; tiene un dibujo especial para ella. Y me ha llamado particularmente la atención el hecho de que, contra lo habitual de otros catecismos pictográficos, cuando tiene que hablar de los muertos, no los represente a la manera indígena, envueltos en un lienzo a modo de sudario; aquí los representa como cadáveres desnudos y con unas marcadas costillas.

\section{Autor}

No hay ni un solo dato que permita aventurar, ni por aproximación, un nombre. Como la mayor parte de estos catecismos, quedan en el anonimato. Al no disponer de escritura española o indígena alguna, tampoco hay nada que permita aventurar una hipótesis. Ni siquiera dan pie a esto los dibujos. En algunos de los catecismos pictográficos conocidos, al presentar el cuarto mandamiento («honrar padre y madre»), la figura del «padre» aparecía representado por un «padre», un religioso, en que era posible en ocasiones distinguir si se trataba de un franciscano (caso del catecismo atribuido a Bernardino de Sahagún, del de Pedro de Gante, o del incompleto), o de un dominico (caso del catecismo tolucano). En esta ocasión la figura del «padre» está representada por un hombre con rasgos indígenas, que aproximaría más la enseñanza a la vida familiar y cotidiana de los destinatarios, pero no permite sospecha alguna sobre el autor.

Como ya he señalado en otra ocasión ${ }^{6}$, estos catecismos son fruto de una estrecha colaboración, en el sentido más pleno del término, entre los misioneros españoles y los tlacuiloque indígenas. Ambos ponían su saber al servicio de una causa, de manera que los catecismos presentaran la genuina fe cristiana, y que fueran captados por la sensibilidad y los ojos de los indios. En esta ocasión, lo enunciado se cumple plenamente, aunque no se sepa nada del autor (inspirador), y sólo sea posible asegurar que el tlacuilo era un indígena, acostumbrado a ver y a dibujar el tipo de personas que aparecen en este pictográfico.

Respecto al tlacuilo o amanuense, es evidentemente un indígena. Los rasgos que aparecen en las facciones de los personajes dibujados no dejan lugar a duda, porque los rostros que pintó se pueden identificar muy fácilmente como

${ }^{6}$ Las siglas de los catecismos citados son: $\mathrm{G}=$ Pedro de Gante; $\mathrm{N}=$ Náhuatl; $\mathrm{T}=$ Tolucano; $\mathrm{S}=$ Sahagún. 
pertenecientes a personas mexicanas. Más aún, cuando aparece en varias ocasiones la figura femenina (hasta en cuatro ocasiones, pic. B94, B100, B109 y B113) consta con un tocado en el que sobresalen dos moños en su pelo, que lo aproximan, por afinidad, a la cultura tolucana. Éste es el único indicio que permite una cierta ubicación geográfica, además del genérico y amplio calificativo de «pictográfico», para designar su inclusión en este selecto grupo, o de «mexicano», que no hace más que describir, sin precisión, su procedencia.

Tampoco existe indicio alguno que permita sospechar que el presente es copia de otro catecismo preexistente. No hay vacilaciones, dudas ni repeticiones en el contenido, lo que parece indicar que se trata de una enseñanza que ya estaba suficientemente consolidada como para evitar torpezas del primer momento, o improvisaciones. Pero es claro que esto no arroja luz alguna sobre el autor.

\section{Fecha}

En cuanto a la fecha de confección, no hay datos. Ya ha aparecido que la descripción genérica de New Catholic Encyclopedia lo ubica en la primera mitad del siglo XVI («probably dating from the first half of the 16th century»). Pero no hay certeza sobre lo afirmado. Y la probabilidad a que hace referencia el texto anterior, podría quedarse en simple posibilidad, porque el procedimiento se continuó utilizando mucho tiempo, y no sólo en la primera parte del XVI. Más aún, la seguridad de trazos y de dibujos, la ausencia de correcciones, y la única constatación de dos faltas (en la omisión de dos líneas verticales de separación) podrían retrasar su fecha hacia la segunda mitad, como si se tratara de una realización más consolidada que en los comienzos, en la primera mitad del XVI. Pero en este punto no hay ningún tipo de certeza.

\section{Contenido}

En cambio, el contenido de los pictogramas sí permite dar un paso adelante. Cuando estudié el catecismo de Pedro de Gante, el Incompleto, y el Mucagua, señalé que

«quien preparó este segundo ejemplar no hizo, por tanto, un catecismo completo. Se limitó a poner únicamente tres formularios -los sacramentos, las obras de misericordia, y la oración por los difuntos- sin intención de que precedieran ni si- 
guieran otros formularios. Tuvo intención, y la llevó a la práctica, de poner sobre el papel, con las mismas medidas que el catecismo de Pedro de Gante, e igualmente en pictogramas distribuidos en cinco bandas, sólo una parte de la doctrina cristiana.

¿Por qué sólo una parte? No hay forma de responder. Ciertamente el contenido de este segundo catecismo no supone la parte más fundamental. La enseñanza sobre la señal de la cruz y las cuatro oraciones básicas -padrenuestro, avemaría, credo y salve- han sido consideradas siempre de primera magnitud, e indispensables en un conocimiento de la fe cristiana. Acaso pretendió que algunos usuarios aprendieran mejor unos formularios que, por ir en último lugar en el Catecismo de Pedro de Gante, habían sido aprendidos peor, u olvidados antes. Incluso el hecho de que añada la oración por los difuntos, que no estaba en el catecismo primero, vuelve a traer a la memoria que los autores, o los amanuenses, tlacuiloque, se movían con gran libertad respecto al contenido de lo presentado, y respecto al orden con que lo dispusieron. El hecho de que este Catecismo incompleto contenga únicamente tres formularios, pero que haya discrepancia al compararlo con el de Pedro de Gante es signo evidente de que lo presentado dependía siempre del criterio de quien realizaba la obra. Y que no había un patrón obligatorio con el que se sintieran vinculados, y que hubieran de seguir forzosamente»?

Si ya existía, y nos ha llegado, un Catecismo incompleto, cuyo contenido no es obligatoriamente toda la doctrina cristiana, sino tan sólo una parte de ella, ahora nos encontramos ante un segundo ejemplar con estas mismas características. La descripción que aparece sobre su contenido señala «The first picture in the top row is the beginning of an exposition of the Fourteen Articles of Faith; the last picture in row 4 is the beginning of an explanation of the Ten Commandments»: los artículos de la fe, y los mandamientos. $Y$ únicamente estos contenidos.

En cambio no resulta válida la indicación que figura al pie de la reproducción en la New Catholic Encyclopedia, al señalar «Fragment of a catechism in Mexican picture». No es un fragmento, puesto que se trata de un texto completo en sí mismo, con un principio y un final perfectamente establecidos. Se inicia con la introducción a los artículos de la fe, y cuando termina queda aún espacio libre en la última banda, que no es aprovechado para nada; no se inicia un nuevo formulario que apareciera incompleto o mutilado, sino

${ }^{7}$ L. REsINES, Diccionario de los catecismos pictográficos, Valladolid, Diputación de Valladolid, 2007, 17-20. 
que no importa demasiado desaprovechar la última parte del papel. Esto mismo sucede en otros pictográficos cuando el amanuense ha completado lo que pretendía dibujar. No es posible, por consiguiente, hablar de fragmento; hay que hablar de catecismo incompleto, o parcial, de catecismo que presenta sólo una parte de la doctrina cristiana, sin pretender más.

El carácter mural que he señalado para este catecismo, por las razones arriba indicadas, me lleva a formular una hipótesis: que este catecismo, en la parte que contiene de la doctrina cristiana, estaba en la pared de la iglesia $u$ otra dependencia conventual, junto con otra serie de cuadros o murales, en los que aparecían otros formularios de la fe cristiana. Si no hay un patrón obligatorio en los contenidos que incluyen para los catecismos pictográficos que conozco, sí es posible afirmar que hay una coincidencia en algunos formularios que parecían fuera de toda cuestión. El Incompleto, de la familia del de Pedro de Gante, solamente incluye los sacramentos, las obras de misericordia y la oración por los difuntos ${ }^{8}$. Por tanto, nada tiene de sorprendente que estemos ante otro catecismo igualmente incompleto, que presenta a sus lectores tan sólo los artículos de la fe y los mandamientos de la ley de Dios. No es disparatado pensar que otros cuadros y hojas, similares a ésta, situados a lo largo de las paredes, ofrecieran a los ojos de los lectores los más comunes formularios en que se condensaba la presentación de la fe cristiana. Así, el aprendizaje por partes resultaba más fácil, y animaba más a emprenderlo el verlo fragmentado por partes, mientras que un todo que pudiera resultar, de entrada, demasiado amplio.

\section{Sentido de la lectura}

En el ya citado estudio, Glass indica que hay varios ejemplares que deben ser leídos por bandas en sentido alternativo: una banda de izquierda a derecha, y a la inversa en la banda siguiente. Es la denominación que se ha llamado boustrophedon, término griego equivalente a arada de buey, que avanza arrastrando el arado haciendo un surco de un extremo al otro del campo, y que hace el surco siguiente desde el punto al que ha llegado hasta el comienzo en la parte contraria.

El Catecismo mazahua ${ }^{9}$ sigue la norma de lectura de izquierda a derecha, salvo en aquellas bandas con las que concluye un formulario, pues en este caso

${ }^{8}$ L. Resines, Catecismos pictográficos de Pedro de Gante, Incompleto y Mucagua, Madrid, Fundación Universitaria Española, 2007, 229.

${ }^{9}$ L. REsines, o.c., 234-239. 
altera el orden para que sean leídas de derecha a izquierda (una serie de pequeñas flechas -posiblemente espurias-lo indican en el original). En el presente catecismo, no hay tales indicaciones en el manuscrito; la descripción reproducida en New Catholic Encyclopedia, sin embargo, lo indica con verdad. Y no sólo para la línea final, sino para todo el conjunto del contenido presentado.

\section{Clasificación y sigla}

El contenido de este ejemplar lo incorpora al grupo de los catecismos pictográficos puros, desde el momento en que no contiene una sola inscripción en letra europea, ni siquiera como forma de pictograma para que fuera utilizada como abreviatura ${ }^{10}$. De los ejemplares que conozco es el prototipo de este grupo, al no incluir nada que no sean pictogramas, pues otros asumen letras que han evolucionado en forma de pictogramas.

No resulta fácil clasificar en un determinado grupo o familia ninguno de los catecismos. Hice un primer esbozo, a sabiendas de que debería ser estudiado mucho más y completado con otros datos ${ }^{11}$. Partiendo, por tanto, de esa dificultad de clasificación, sí que encuentro una similitud plástica entre el Catecismo náhuatl, y el presente. El pictograma N3, que significa Señor, ofrece una cabeza con una corona historiada, que aumenta su volumen, y en la que hay unos trazos que determinan como un sombrero ahuecado o una corona regia. Algo similar aparece en éste, en los pictogramas 5, 10, 14... (B5, B10, B14...). Pero un sólo rasgo es poco para una clasificación rigurosa.

Por otro lado, ya indiqué antes que el adorno en el peinado de la mujer (B94, B100, B109, B112) lo aproximan al Catecismo tolucano, donde la mujer aparece representada con un adorno semejante (por ejemplo, T253) ${ }^{12}$. Pero, por la misma razón, un solo rasgo tampoco obliga a formar un grupo con el presente y el Tolucano.

Acabo de referirme a algunos pictogramas del presente catecismo. Como he optado por un sistema que asigna una letra, una sigla, a cada catecismo, que lo diferencia del resto, y a continuación el número del pictograma, para poder hacer referencia a cada catecismo y a cada pictograma en parti-

10 L. RESINES, Estudio sobre el catecismo pictográfico mazahua, en "Estudio Agustiniano" 29 (1994) 243-306.

11 L. REsINEs, Diccionario de los catecismos pictográficos, Valladolid, Diputación de Valladolid, 2007, 39-41.

12 L. RESINES, Diccionario de los catecismos pictográficos, Valladolid, Diputación de Valladolid, 2007, 67-69. 
cular, el presente catecismo lleva la sigla "B", por hallarse en Berlín. Y sus pictogramas se designan como B5, B10, B14,... tal como acabo de hacer.

\section{Desciframiento}

A diferencia de otros catecismos pictográficos, el presente está completamente subdividido en escenas por las líneas verticales a que hice referencia. En otros catecismos aparecen en algunas ocasiones, pero no en la totalidad del catecismo. Por tanto, en este caso es posible hablar de «escenas», referidas a cada uno de los artículos de la fe, o de los mandamientos. En cambio, en otros catecismos suele haber un pictograma o unas líneas verticales adornadas, anchas, que marcan el final de un formulario y el comienzo del siguiente; el final, además, suele estar rematado por el «Amén», cosa que no sucede en este caso en ninguno de los dos formularios que incluye, los artículos de la fe, y los mandamientos de la ley de Dios. Eso deja en particular un cierto margen de duda en una serie de «escenas» que, situadas entre ambos formularios, y más difíciles de descifrar, no resulta claro si pertenecen al final de los artículos de la fe, o al comienzo de los mandamientos. Con ese margen de duda, me ha parecido más lógico -como aparecerá más adelante-incluirlas en el final de los artículos de la fe (que abarcarían, de esta forma, hasta la «escena» $22^{a}$ ).

I PARTE. ARTÍ́cULOS DE LA FE

\section{Pictograma B1}

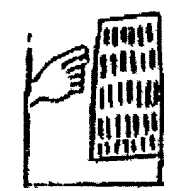

Desde la parte izquierda aparece una mano que señala a un rectángulo, dispuesto en vertical, que incluye cinco estratos de pequeñas líneas verticales, haciendo que el fondo aparezca todo él rayado. La mano sola, indicadora, muy frecuente en otros catecismos pictográficos (p. ej. en Catecismo náhuatl), o el personaje completo que señala con la mano (p. ej. en el atribuido a Bernardino de Sahagún) aparece aquí sólo en tres ocasiones. En este pictograma B1, más B68 y B77.

La impericia del amanuense dibuja una mano en la que no hay un dedo pulgar oponible, ni existe proporción en la longitud de los demás dedos; en B68 hay un dedo que quería ser el índice, más largo, pero que está el primero y que corresponde al pulgar. Al ser meramente indicadora, la mano puede carecer de significado propio, o asignarle el de éstos. 
El rectángulo rayado o sombreado ha sido empleado con frecuencia en otros catecismos pictográficos. Su significado es claro: artículos de la fe.

El conjunto de este pictograma compuesto es: éstos [son] artículos de la fe.

\section{Pictograma B2}

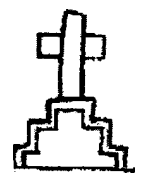

Una cruz grande colocada sobre una peana con tres escalones. Muy parecido a G4, donde significa precisamente cruz, aquí, por dar fluidez a la frase, parece que pudiera encajar mejor el sentido de cristiana.

\section{Pictograma B3}

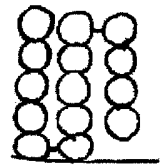

Aparecen catorce círculos: dos grupos de cinco, dispuesto en vertical, a la izquierda, más uno de cuatro, a la derecha, unido al anterior por una pequeña línea. Forma parte del extendido sistema de contabilidad que figura en numerosos catecismos pictográficos. Su sentido es claro: [son] catorce.

Se completa la escena $1^{\text {a }}$, de introducción: éstos [son] artículos de la fe cristiana, [son] catorce.

\section{Pictograma B4}

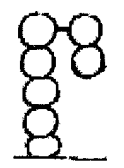

Un numeral: una fila vertical de cinco círculos, unidos por una línea a otros dos en vertical, paralelos a los anteriores. Su significado es: siete.

\section{Pictograma B5}

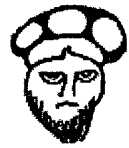

Un rostro de frente, con ojos, nariz, boca y barba. Tiene una corona por encima de la parte superior de la cabeza, casi a modo de sombrero; en la corona están inscritos tres círculos blancos, delimitados por trazos oscuros. El rostro, acompañado de la corona, tiene una clara semejanza con el pictograma que aparece en el Catecismo náhuatl (N3). Se ve claro que tiene el mismo significado: Dios.

Se completa la $2^{a}$ escena, cuyo sentido es: siete [para] Dios. 


\section{Pictograma B6}

8

Muy parecido al pictograma B4, con la diferencia de que la 88 línea paralela formada sólo por dos círculos arranca desde abajo en 00 lugar de hacerlo desde arriba. Mantiene, sin embargo, el sentido idéntico: siete.

\section{Pictograma B7}

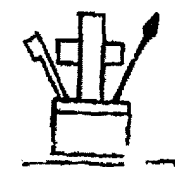

Una base rectangular, casi cuadrada, con una línea a modo de remate por la parte superior, soporta una cruz en el centro (parecida a la de $\mathrm{B} 2$, con distinta base), flanqueada a la izquierda por una vara un poco más ancha en la parte superior, y a la derecha por una lanza. El conjunto recuerda los atributos de la pasión de Jesús, por lo que la vara de la izquierda, con el remate del extremo, ha de ser entendida como una esponja. El sentido directo del dibujo podría entenderse como equivalente a «pasión»; pero dado que el formulario de los artículos de la fe se refiere a la humanidad de Cristo, y que aquí no aparece la imagen que correspondería a Jesús, su equivalencia ha de ser: humanidad. friente.

El hecho de emplear elementos de la pasión habla de la humanidad su-

Es la $3^{\text {a }}$ escena, cuyo sentido es: siete [para la] humanidad.

\section{Pictograma B8}

88 Igual al pictograma $\mathrm{B} 4$, con el mismo significado numérico:

\section{Pictograma B9}

Repite, con forma menos alargada, el pictograma B1, aunque en esta ocasión carezca de la mano indicadora que figuraba al comienzo. Conserva el mismo sentido: artículos de la fe.

\section{Pictograma B10}

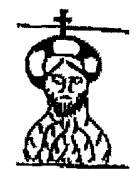

Muy parecido al pictograma B5, figura el mismo rostro de índole divina. Las diferencias con respecto a aquél son: que en esta ocasión la corona está rematada por una pequeña cruz en la 
parte superior, que traspasa el límite superior de la banda horizontal, hasta el extremo superior del papel; y que la cabeza del pictograma B5 está seguida por el cuerpo. Tanto éste, como todos los cuerpos que aparecen en este catecismo pictográfico (salvo las excepciones que aparecerán en su momento) son rechonchos, en forma de tronco de pirámide, rematados por la cabeza, con unas líneas onduladas que caen por los lados hasta el suelo, y otras interiores que marcan pliegues en el vestido. En este caso no se adivinan manos ni pies, ocultos en el bulto corporal (otras veces aparece alguna mano). Las dos diferencias señaladas entre este pictograma B10 y el anterior, B5, no hacen que cambie su sentido, que es: Dios.

Se completa la $4^{\mathrm{a}}$ escena, que expresa: [los] siete artículos de la fe [para] Dios.

\section{Pictograma B11} Un círculo único en la parte superior equivale al ordinal: [el]
primero.

\section{Pictograma B12}

Idéntico al pictograma B9, está situado por debajo del pictograma anterior; tiene el mismo sentido que aquél: artículo de la fe.

\section{Pictograma B13}

Hay dibujado un rectángulo en posición apaisada en la parte 1998 inferior de la banda, a la derecha de la escena. A diferencia del Bxy rectángulo que apareció en B1, B9,... el que nos ocupa está relleno por cuatro niveles de pequeños círculos unidos entre sí, apretados, que llenan el interior del rectángulo. El pictograma B13 está unido por una pequeña línea al anterior, el B12, como continuación entre ellos. Una característica propia de este catecismo es disponer los diversos pictogramas en los espacios reservados para cada escena y organizarlos dentro de ella en el orden que le parece oportuno, como si se tratara de una unidad, aunque no siga siempre un orden claro para la lectura. Este dibujo no aparece más veces en el catecismo. El significado más probable de este pictograma es: creer. 


\section{Pictograma B14}

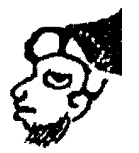

Dibujo similar al del pictograma B5, con la diferencia de que el rostro aparece de perfil, y no de frente. A lo largo del catecismo, aparecerá en varias ocasiones de cualquiera de las dos formas, sin que esto lleve consigo variación en su equivalencia: Dios.

La escena quinta, en consecuencia, es: [el] primer artículo de la fe creer [en] Dios.

\section{Pictograma B15}

0

Falta, por desgarro del ángulo superior derecho del papel. Se intuye, sin embargo, por la progresión del texto, que el que debería figurar aquí es un ordinal formado por dos círculos dispuestos en vertical, como sucede con el pictograma B43, que tiene el mismo sentido: [el] segundo.

\section{Pictograma B16}

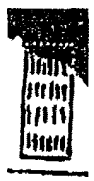

Levemente mutilado en la parte superior, se ve perfectamente el rectángulo que aparece en numerosas ocasiones en este catecismo, y cuyo sentido es: artículo de la fe.

\section{Pictograma B17 (restaurado)}

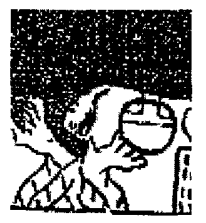

Figura mutilada, de la que consta la parte inferior, el cuerpo informe, como está descrito antes para casi todas las ocasiones; del mismo brotan las dos manos, y la de la derecha del lector (la izquierda de la figura dibujada) sostiene la bola del mundo, o la tierra, como está dibujada en multitud de ocasiones en los catecismos pictográficos ${ }^{13}$. La cabeza, que también falta, debería corresponder a la misma del pictograma B10. Por consiguiente, estos dos pictogramas B10 y B17 se diferenciarían en que en el segundo aparecen las manos, una de las cuales sostiene la tierra. El sentido del formulario indica que la equivalencia ha de ser: Dios Padre.

Aquí se completa la escena $6^{a}$, pero el amanuense tuvo un fallo porque omitió la línea vertical de separación entre ésta escena y la siguiente; falta la

13 L. RESINES, Estudio sobre el catecismo pictográfico tolucano, en "Estudio Agustiniano" 31 (1996) 245-298; ID., Diccionario de los catecismos pictográficos, Valladolid, Diputación de Valladolid, 2007, 60. 
parte superior de ambas, pero no la parte inferior, y en ella no existe muestra alguna de que estuviera hecho el trazo. La escena $6^{\mathrm{a}}$, completa, y reconstruida en parte, sería: [el] segundo artículo de la fe, Dios Padre.

\section{Pictograma B18}

8

El desgarro referido sólo permite ver un círculo completo, y otro parcial sobre él; es claro que además de éste, tendría que haber otro más por encima, para significar: tercero.

\section{Pictograma B19}

举果 Bajo el pictograma B18, aparece el ya repetido rectángulo, comhill pleto, que equivale a: artículo de la fe.

\section{Pictograma B20 (restaurado)}

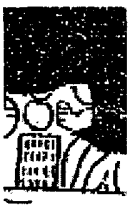

La figura mutilada, de la cual aparece sólo la parte inferior del cuerpo, sí muestra una mano, la izquierda, y no es posible saber si también la otra; como tampoco es posible saber si el rostro estaría dibujado de frente o de perfil: un mínimo trazo justo por encima de la mano indicada no permite deducir nada más. Sin embargo, el discurrir del formulario da pie para suponer la imagen que corresponde a Jesús, que podría ser parecida al pictograma B40. Éste sería, por tanto, el significado: [el Hijo].

Los pictogramas B18, B19 y B20 constituyen la escena $7^{\text {a }}$, cuyo sentido completo es: [el] tercer artículo de la fe, [el Hijo].

\section{Pictograma B21}

El roto del papel, por el extremo izquierdo deja ver dos círculos, 8 de los cuatro que tendría que haber para proseguir la numeración.

8 Por tanto, su sentido es el ordinal: cuarto

\section{Pictograma B22}

Aparece, repetido, el rectángulo rayado, que ha salido en varias ocasiones; en este dibujo le falta una pequeña parte de su ángulo inferior derecho: artículo de la fe. 


\section{Pictograma B23}

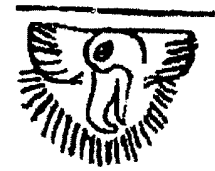

En la parte superior de la banda está dibujada una cabeza de pájaro con largo pico hacia abajo (con un parecido a un alcatraz); tiene en torno a la cabeza una corona marcada por dos trazos circulares, con líneas interiores. Podrían ser también alas. Una segunda corona, o aureola, más amplia, rodea enteramente cabeza y pico. Refuerza la corona anterior, y expresa con rotundidad el carácter divino. La representación plástica de un pájaro (no exactamente paloma, desconocida para el tlacuilo) ha sido un recurso habitual para la representación del Espíritu Santo, como es el caso presente.

Esta escena 8 completa dice así: [el] cuarto artículo de la fe [el] Espíritu Santo.

\section{Pictograma B24}

8 Una fila vertical de cinco círculos pequeños expresa el ordinal:

\section{Pictograma B25}

A continuación, avanzando hacia la izquierda en el sentido de la lectura, hay dispuestos tres pictogramas uno sobre otro. Creo que el sentido más adecuado es decantarse en primer lugar por el que está en el centro. Representa, apaisado, el rectángulo rayado, tan repetido, que indica artículo de la fe.

\section{Pictograma B26}

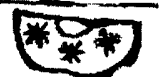

Por encima del pictograma anterior, justo hasta el límite superior de la banda hay un semicírculo, en cuyo interior aparece otro más pequeño central, y tres estrellas que lo rodean. Es la forma de representar el sol y las estrellas. El conjunto del pictograma tiene un claro significado: cielo.

\section{Pictograma B27}

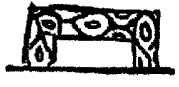

En la parte central de la escena, en el nivel inferior, este pictograma no repetido muestra una especie de mesa (tablero y dos patas), adornados en el frente que se muestra al lector. $\mathrm{Al}$ ser pictograma con única presencia, y no tener sencilla correspondencia con 
los de otros catecismos, no es fácil darle un significado. Pero el más lógico sería: tierra.

\section{Pictograma B28}

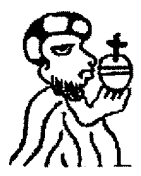

En la parte izquierda de la escena figura una imagen parecida a la del pictograma B10, que representaba a Dios Padre, y supuestamente parecida a la mutilada que figuraría, caso de estar completa, en B17. La de B17 aparecería de frente, porque se ven ambas manos a los lados, mientras que la que nos ocupa, B28, está de perfil. Pero sí consta una mano con la que sostiene la representación de la bola del mundo, rematado con una cruz en la parte superior. En continuidad con el pictograma anterior, habría que asignar ahora el sentido más restrictivo de hace.

La escena $9^{a}$ vendría a decir lo siguiente: [el] quinto artículo de la fe, [el] cielo [y la] tierra Dios hace.

\section{Pictograma B29}

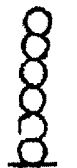

Son seis los circulitos dispuestos en vertical; se repite en el pictograma B60, igual al presente. Su significado es el ordinal: sexto.

\section{Pictograma B30}

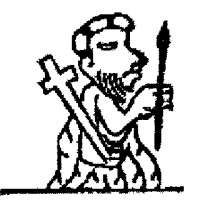

Una figura de perfil, con corona que denota su carácter divino, mira hacia la derecha del lector; porta en su mano derecha (la única que se ve) una lanza vertical; y a su espalda, sobrepuesta, aunque sin ningún tipo de sujeción, hay una cruz. El sentido que podría asignarse a este pictograma no se impone con evidencia por su contemplación, y es más seguro acudir a lo que dice el formulario, para atribuirle el equivalente de: salvador.

La breve escena $10^{\mathrm{a}}$, constituida por estos dos pictogramas, queda como: [el] sexto [es] salvador.

\section{Pictograma B31}

Con un tamaño algo reducido por comparación con otras ocasiones, aparece el rectángulo rayado que representa artículo de la fe. 


\section{Pictograma B32}<smiles></smiles>

En dos filas, de cinco y dos, en vertical, unidos entre sí por un trazo, hay siete círculos. A diferencia del pictograma B8, la segunda fila con dos círculos está conectada con la anterior por la parte inferior de la banda. Representa el ordinal: séptimo.

En esta ocasión se produce un curioso cambio de orden respecto a lo que viene siendo habitual, porque lo visto era que aparecía primero el ordinal y después la denominación sustantivada de artículo de la fe; aquí, sin razón aparente, se ha invertido el orden, sin que sufra el significado.

\section{Pictograma B33}

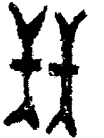

Hay dos barras (o trazos, si se prefiere), anchos, en negro, de tamaño bastante destacado. Están dibujadas en posición vertical. Ambas tienen en sus extremos inferior y superior un remate, como una "V", con el mismo trazo grueso y negro. Y también disponen a la mitad, de una pequeña raya perpendicular gruesa y negra. Aquí aparece repetido o duplicado, mientras que en los pictogramas B75 y B78 sólo consta una vez. Por cotejo con estos pictogramas, y por continuidad con el formulario que desgrana el catecismo, parece que el sentido que mejor encaja sería el de gloria (aunque el plural «glorias» resulte forzado).

\section{Pictograma B34}

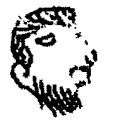

Aparece una cabeza humana, de perfil, sin corona (no hay, pues, connotación divina), con barba. En los pictogramas B73 y B75 (aunque estén imberbes), tiene el sentido de alma, que aquí le encaja bien, si se acepta la significación propuesta para el pictograma anterior, B33, pues se corresponde con el formulario.

La significación de la escena $11^{a}$ sería: [el] artículo de la fe séptimo [da] gloria al alma [humana].

Se completa de esta forma la serie de los artículos que corresponden a la divinidad, y se inicia la segunda serie del formulario, la de los artículos que corresponden a la humanidad de Jesús.

\section{Pictograma B35}

Un círculo alberga en su interior, a derecha e izquierda unas pequeñas rayas, como si se tratara de una concha; refuerza más está impresión una pe- 
queña corona circular incompleta en la parte opuesta, en la parte superior. No tiene ninguna otra representación en este catecismo, ni hay forma de compararlo con otros catecismos pictográficos conocidos. Sólo se me ocurre, por lógica, que podría tener el sentido de la conjunción $y$, aunque en otros momentos en que podría aparecer tal partícula no aparece este pictograma.

\section{Pictograma B36}

Los mismos siete círculos del pictograma B6, aunque dispuesto de arriba hacia abajo, en lugar de la posición que tenían en aquél. No cambia su equivalencia: siete.

\section{Pictograma B37}

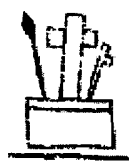

Idéntico al pictograma B7, con la diferencia de que la lanza y la esponja están cambiadas de posición; pero es preciso recordar que esta segunda banda en la que se encuentra este pictograma se lee de derecha a izquierda, y no de izquierda a derecha, como se leía en la banda superior. Le cabe el significado idéntico: humanidad.

Los tres pictogramas últimos constituyen la escena $12^{\mathrm{a}}: y$ [los] siete [para la] humanidad.

\section{Pictograma B38}

Igual al pictograma B11, con la misma equivalencia ordinal: [el]
primero.

\section{Pictograma B39}

Alojado bajo el anterior, un dibujo idéntico al del pictograma B12: artículo de la fe.

\section{Pictograma B40}

Una cabeza, similar, a la que aparecía en B34, pero dotada de corona divina, se refiere concretamente a Jesús de quien hablan los artículos de esta serie segunda. Éste es, por tanto, su sentido: Jesús. 


\section{Pictograma B41}

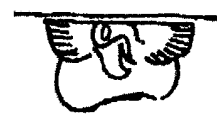

Es un dibujo parecido, aunque más pequeño y menos detallado que B23. Está situado en la parte superior de la banda, por encima del pictograma anterior, B40. Conserva la misma equivalencia: [por el] Espíritu Santo.

\section{Pictograma B42}

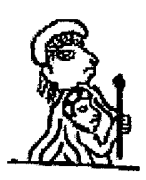

Se trata de un pictograma compuesto, o doble; en él aparece la figura de una mujer (reconocible por el cabello largo apuntado en la parte posterior de la cabeza. Su cuerpo y vestido llegan hasta el suelo, como suele ser ordinario en los dibujos de este catecismo. Pero en el interior del espacio destinado al cuerpo, en tamaño más pequeño, aparece otra figura que dispone de corona (atributo de divinidad), como su hijo, todavía recluido en su seno. Llama la atención que el Niño divino porte en sus manos una lanza que sale de la silueta del dibujo de la mujer madre. El sentido del pictograma aparece bastante claro: concebido [por] María.

La escena que abarca los pictogramas B38 a B42 es: [el] primer artículo de la fe, Jesús [por el] Espíritu Santo [es] concebido [por] María.

\section{Pictograma B43}

Dos círculos en vertical (como los que se supone constituirían el
pictograma B15) tienen la equivalencia del ordinal: [el] segundo.
Hay una observación que hacer, que no supone precisamente fallo, sino simple omisión: consta el numeral segundo, pero no figura el pictograma que haría referencia al consabido artículo de la fe.

\section{Pictograma B44}

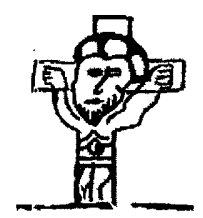

Representación indudable de Cristo en la cruz. Una cruz grande ocupa toda la altura de la banda, y en ella aparece clavado Jesús. Se reconoce su cara de frente, con la corona divina; los brazos alzados (muy toscos) elevan las manos hasta el travesaño horizontal de la cruz; están marcadas las costillas, una doble línea horizontal marca el paño de pureza, y unas toscas piernas (no se ven los pies), llegan hasta el nivel inferior de la banda. La desproporción de la figura es notoria. A diferencia de otros pictogramas de algunos catecismos pictográficos, no aparecen signos que evidencien clavos, en tanto que en otras ocasiones éstos aparecen marcados e incluso exagerados. La equivalencia del pictograma no ofrece duda: Jesús crucificado. 


\section{Pictograma B45}

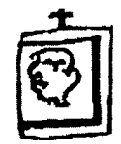

En un doble recuadro, que está rematado en la parte superior por una pequeña cruz, aparece dibujada una cabeza. El significado de este pictograma podría oscilar entre almas (se verá más claro el contraste en los pictogramas B74 y B75), hombres o también pecadores (aunque no haya ninguna muestra que aluda al pecado, como aparece en otros pictográficos más extensos). Prefiero decantarme por esta última posibilidad: pecadores.

La totalidad de la escena $14^{\mathrm{a}}$ es, por consiguiente: [el] segundo, Jesús crucificado [por los] pecadores.

\section{Pictograma B46}

Pictograma íntegro, por comparación con el que debería figurar en B18, mutilado: tres círculos verticales muestran el ordinal: tercero.

\section{Pictograma B47}

Muestra el consabido rectángulo rayado que el amanuense Lü. había omitido en la escena anterior. Dice: artículo de la fe.

\section{Pictograma B48}

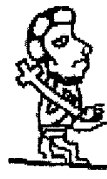

Complejo y compuesto pictograma constituido por varios elementos. El primero, a la izquierda, es la imagen de Jesús, similar a la del pictograma anterior, pero sin estar fijo a la cruz; los mismos rasgos, la misma desproporción y toscos dibujos: unas piernas torcidas dejan ver los pies que no aparecían en B44. La diferencia es que porta una pequeña cruz al hombro: es el signo de la victoria obtenida en su muerte. La representación no tiene -como en otros pictográficos, y en este mismo en el pictograma B57- una escalera que indique el descenso. Simplemente lo muestra ya habiendo descendido, según la expresión compartida por el credo y por el formulario de los artículos.

Este Jesús que ha bajado, lo ha hecho al infierno. Esto es lo que muestra: Jesús bajó.

\section{Pictograma B49}

Está representado por una cabeza animal, monstruosa, de grandes dimensiones, con las fauces dentadas abiertas. Los pictográficos han represen- 


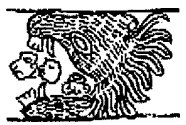

tado así al infierno, siguiendo una larga tradición pictórica europea, llevada por los misioneros. Por la derecha, el cuerpo del monstruo se difumina en una amplia melena.

Aún hay dos detalles más. Entre los dientes de la bestia infernal hay dos cabezas de perfil (la segunda incluso con el párpado cerrado): es la representación de las almas, que en este pictograma cobra toda su fuerza expresiva y permite trasladar su significado a otros pictogramas de este mismo manuscrito (B34, B73, B75). El otro detalle es que todavía más en el interior de las fauces, una figura geométrica, como un círculo rematado por volutas en la parte inferior, con un adorno en la superior, y una estrecha banda en el centro adquiere todo su sentido: [que] esperan (aparece también este mismo pictograma, más grande y nítido en B76).

Este complejo pictograma tiene la equivalencia siguiente:Jesús bajó [al] infierno [y] sacó las almas [que] esperaban.

La escena completa, uniendo a éste los tres pictogramas precedentes es: [el] tercer artículo de la fe, Jesús bajó [al] infierno [y] sacó las almas [que] esperaban.

\section{Pictograma B50}

Con él da inicio la escena $16^{\mathrm{a}}$. Es, completo, una línea de cuatro cír-
culos, como la que tendría que figurar en el pictograma B21. Significa:
[el] cuarto.

\section{Pictograma B51}

Justo al lado del anterior, aparece el rectángulo rayado: artículo diming de la fe.

\section{Pictograma B52}

También es un pictograma que tiene una representación única: tres finas líneas verticales, paralelas entre sí; las dos primeras se unen entre sí por la parte superior, y la segunda y tercera también por la parte inferior. Forman un conjunto de tres elementos seguidos, que constituyen una unidad. El sentido que parece encajar, sin demasiada duda, es: [al] tercer día.

\section{Pictograma B53}

Está dibujada la figura de Jesús, pero en lugar de estar desnuda, como en B44 o B48), en esta ocasión aparece vestida (con el consabido ropaje tron- 
copiramidal), y porta una lanza en la mano. Está orientado hacia la izquierda (está banda se lee de izquierda a derecha). El sentido que reclama el formulario es: resucitó.

\section{Pictograma B54}

Dos figuras humanas están tendidas horizontalmente, una

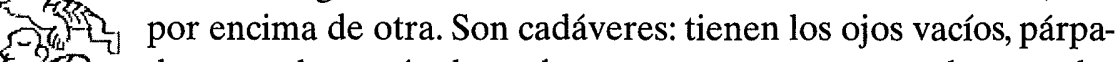
造运 dos cerrados, están desnudos, y se remarcan exageradamente las costillas, consecuencia de la muerte. Son: los muertos.

La presente escena, $16^{\text {a }}$, incluye esta afirmación: [el] cuarto artículo de la fe, [al] tercer día Jesús resucitó [de entre] los muertos.

\section{Pictograma B55}

Q Una hilera vertical de cinco círculos, presenta el número: [el]

\section{Pictograma B56}

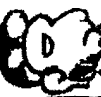

Aparece una cabeza, con corona divina, que la identifica con Jesús (como B40). Está en una posición extraña, horizontal mirando hacia arriba, pero es que todo el conjunto de la escena tiene un cierto desorden y, en este caso, hay que ir leyéndola en sentido contrario al del reloj. Si la hubiera dibujado en posición vertical no hubiera cabido el pictograma que está por encima de ella. El sentido es: Jesús.

\section{Pictograma B57}

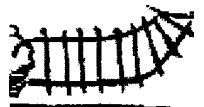

Un curioso dibujo en la parte inferior de la banda, que representa una escalera, pero cuyos largueros, en lugar de ser rectos, giran hacia la izquierda para poder empalmar con el pictograma siguiente, que aparece en la parte superior de la banda. En otros catecismos pictográficos hay otros dibujos que incluyen la escalera (G117, M179, S 157,...). La idea que representa es muy clara: subió.

\section{Pictograma B58}

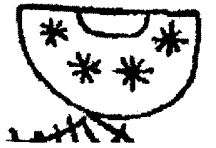

Idéntico al pictograma B26, con la única diferencia de que aquél albergaba tres estrellas, mientras que éste, un poco más grande, da cabida a cuatro. Su significado es obvio: el cielo. 


\section{Pictograma B59}

A la izquierda del pictograma anterior surge una mano

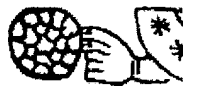
(zafia, con todos los dedos de la misma longitud), que apunta a un círculo que está encima del pictograma B56; dicho círculo está repleto de pequeños círculos que ocupan toda su superficie. Por el sentido del formulario, y un poco por la expresión del dibujo es posible deducir el sentido completo del pictograma: a la derecha sentado. No aparece el pictograma que representa a Dios Padre (B17), que parecería completar la idea.

Es la escena $17^{\mathrm{a}}$ que viene a decir: [el] quinto, Jesús subió al cielo, a la derecha sentado.

\section{Pictograma B60}

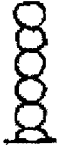

Una hilera vertical de seis círculos, igual al pictograma B29, significa: [el] sexto.

\section{Pictograma B61}

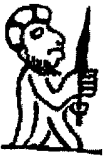

Representa la persona de Jesús, con cuerpo completo, quien sostiene en sus manos una espada, agarrada por la hoja, con la punta hacia arriba. (La misma espada volverá a aparecer en B96, con un sentido que allí, por el contexto, aparece claro). Aquí únicamente por conjeturas, podría asignarse un significado. El recurso a otros pictográficos muestra la espada en dos catecismos emparentados entre sí,T205 y S164;pero es más evidente aún en N184, en que figura Jesús, con una espada en la mano, puesta al cuello de la persona que es juzgada. Su equivalencia, por tanto, sería:Jesús juzga.

\section{Pictograma B62}

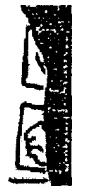

Está casi desaparecido por el desgarro del papel. Aparecen dos cuadrados, y en el que está en la parte inferior se llega a ver un rostro humano; en el de la parte superior, el trazo conservado no permite suponer nada. Sólo por el sentido del contexto, se podría aventurar que hay otro rostro. La equivalencia que se podría proponer como hipótesis es: [a los] hombres.

En las escenas $17^{\mathrm{a}}$ y $18^{\mathrm{a}}$ el amanuense ha omitido el pictograma que correspondería a artículo de la fe, como sucedió en la $14^{\mathrm{a}}$, por falta de espacio.

Con ello se completa la escena $18^{\mathrm{a}}$, que quedaría como: [el] sexto, Jesús juzga [a los] hombres. 
Pictograma B63 (restaurado)

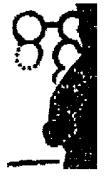

El pictograma está deteriorado, pero resulta fácil suplirlo. El ordinal representado por una fila de círculos, cinco, unidos por una línea a otros dos en la parte superior: [el] séptimo.

\section{Pictograma B64}

Retorna el pictograma del rectángulo rayado, que significa: artículo
dining
initud da fe.

\section{Pictograma B65}

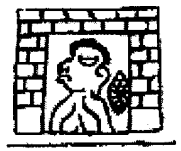

En el interior de un edificio o construcción, hecho de sillares o ladrillos, sólido, aparece dibujado un hombre; a la derecha hay una figura oval, llena de pequeños círculos. El hombre mira hacia la izquierda, como si la rechazara. No es fácil descifrarlo, por ser absolutamente nuevo, pero el contexto del formulario podría apuntar la idea de castigo, o de cárcel, donde se le ve encerrado.

\section{Pictograma B66}

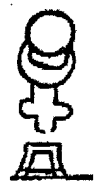

No es claro si se trata de un único pictograma o de dos superpuestos. En la parte superior, un círculo se apoya en los dos extremos de una media luna que aparece bajo él y casi tangente al mismo. Esa media luna, a su vez tiene debajo una figura como una cruz; pero es evidente que no es una cruz, en el sentido religioso, porque cuando han aparecido en este catecismo (B2, B4, B44, B48) tienen otra representación completamente diversa. Más abajo aún, en el umbral inferior de la banda, aparece el dibujo de un taburete, o una mesita, que recuerda a B27 (con el sentido de hacer), pero mucho más pequeña y sin adorno alguno.

No he sido capaz de encontrar sentido alguno para este pictograma, $\mathrm{ni}$ por comparación con otros catecismos, ni por el contexto literario.

\section{Pictograma B67}

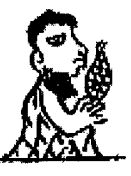

Un dibujo de un hombre (sin corona divina), pero con barba (los indios eran lampiños, por consiguiente podría ser un español) que tiene en sus manos un óvalo igual que el que aparecía en B65. Podría ser perfectamente el dibujo de una mazorca de maíz. Por el 
contexto literario del formulario de los artículos de la fe, se le puede asignar, por contraste, el sentido de:premio.

Se completa así la escena $19^{a}$, cuyo sentido, con lagunas, sería: [el] séptimo artículo de la fe, castigo (....) [o] premio.

Las tres escenas siguientes podrían ser el final de los artículos de la fe, en una especie de comentario, no habitual en el formulario, o podrían ser una introducción, tampoco corriente, a los mandamientos que constituyen la segunda parte del catecismo. Me inclino, tras haberlas examinado, por la primera posibilidad, de constituir una prolongación de los artículos de la fe, principalmente apoyado en el pictograma B69, en que vuelve a aparecer esa representación.

\section{Pictograma B68}

Una mano indicativa, como B1, apunta, con un dedo índice, excepcionalmente más largo, a un círculo. El sentido del pictograma sería, pues: este primer.

\section{Pictograma B69}

Aparece el rectángulo rayado que había sido habitual a lo largo de la exposición de este formulario de la fe cristiana: artículo de la fe.

\section{Pictograma B70}

También en esta ocasión he dudado si se trata de un pictograma sólo o de dos. Pero la dificultad de descifrarlo, al no encontrar similitud, ni tampoco sentido en el texto de los artículos de la fe, me ha llevado a dejarlo por uno, no resuelto. La descripción es la siguiente: en la parte inferior un círculo grande (no pequeño, como cuando se trata de números), lleva inscrita en su parte inferior una cruz en posición vertical; sobre este círculo, la mitad inferior de otro círculo apa : e rayada en oblicuo. No he encontrado sentido que encajase con esta representación.

La escena $20^{\mathrm{a}}$, imprecisa, se resiente de falta de sentido: este primer artículo de la fe...

\section{Pictograma B71}

Por última vez figura el rectángulo rayado, tan repetido; en

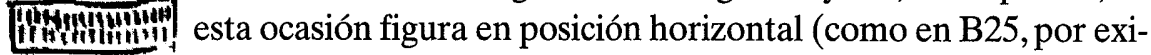
gencias de la composición de la escena), pero con el mismo sentido; ocupa la parte superior derecha de la escena: artículo de la fe. 


\section{Pictograma B72}

It in in Bajo el pictograma anterior aparecen dibujadas dos hileras I I I horizontales de un mismo dibujo repetido: una simple línea obli1) cua, que baja de izquierda a derecha, de la cual se desprenden tres rayas verticales pequeñas. En la hilera superior se repite cuatro veces, y en la inferior, cinco; las cuatro de arriba están alineadas en vertical con las cuatro primeras de abajo, y la quinta, a la derecha, no tiene correspondencia en la hilera superior. Me ha parecido, sólo como posible, para que hiciera sentido con los pictogramas que siguen, que se le podría asignar el sentido de: salvar.

\section{Pictograma B73}

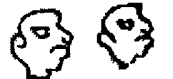

En un único pictograma he incluido cuatro cabezas, dis-3 genes, en plural, formando parte del pictograma compuesto B49, que expresaba que Jesús bajó al infierno a sacar las almas que allí estaban. Su sentido, por consiguiente, es bastante claro: las almas.

La escena $21^{\mathrm{a}}$ quedaría, en conjunto como sigue: [los] artículos de la fe salvan (?) las almas

\section{Pictograma B74}

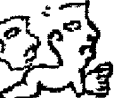

Una cabeza humana, suelta, como apareció en B73 y antes en B49, señala la misma idea: alma.

\section{Pictograma B75}

Se repite (aquí una sola vez) el mismo dibujo del pictograma B33.
Tiene, pues, la misma equivalencia: gloria

\section{Pictograma B76}

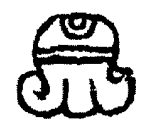

También es un pictograma repetido, pero en esta ocasión de mayor tamaño que cuando apareció en B49: Jesús bajó al infierno a sacar las almas que esperaban. Este mismo sentido le cuadra aquí: esperar.

También es un pictograma repetido, pero en esta ocasión de mayor tamaño que cuando apareció en B49: Jesús bajó a infierno a sacar las almas que esperaban. Este mismo sentido le cuadra aquí: esperar. 
La escena $22^{\mathrm{a}}$, con la que concluye el formulario de los artículos de la fe, dice así: [al] cuerpo [y al] alma [la] gloria espera.

Se completa así este formulario, con una especie de comentario final. Hay que hacer una observación respecto a esta representación de los artículos de la fe en el presente catecismo. La serie primera de artículos que miran a la divinidad se ajusta a los formularios habituales, procedentes del medievo, y mantenidos después durante siglos, particularmente por la catequesis española, con más fuerza que en otros países. En cambio, en la serie segunda, la que se refiere a los artículos que hacen referencia a Jesús hecho hombre, el presente catecismo ha introducido algún cambio. Ha omitido el tradicional artículo segundo, que, después de la concepción, señalaba que Jesús nació de santa María. En consecuencia, los artículos que siguen han adelantado la numeración, pero el séptimo lo ha dividido en dos: el sexto que habla de que Jesús juzgará (si es válida la interpretación dada), y el séptimo que expresa el premio o castigo, con la explicación última de que, si se aceptan estos artículos, se salvan los cuerpos y almas de los que esperan la gloria ${ }^{14}$.

Todo el formulario de los artículos de la fe, casi descifrado en su totalidad, en sus dos septenas, es:

Éstos [son] artículos de la fe cristiana, [son] catorce. Siete [para] Dios, siete [para la] humanidad. [Los] siete artículos de la fe [para] Dios: [el] primer artículo de la fe creer [en] Dios. [El segundo] artículo de la fe, Dios Padre. [El] tercer artículo de la fe, [el Hijo]. [El] cuarto artículo de la fe [el] Espiritu Santo. [El] quinto artículo de la fe, [el] cielo [y la] tierra Dios hace. [El] sexto, [es] salvador. [El] artículo de la fe séptimo, [da] gloria al alma [humana].

Y [los] siete [para la] humanidad: [el] primer artículo de la fe, Jesús [por el] Espíritu Santo [es] concebido [por] María. [El] segundo, Jesús crucificado [por los] pecadores. [El] tercer artículo de la fe, Jesús bajó [al] infierno [y] sacó las almas [que] esperaban. [El] cuarto artículo de la fe, [al] tercer día Jesús resucitó [de entre] los muertos. [El] quinto, Jesús subió al cielo, a la derecha sentado. [El] sexto, Jesús juzga [a los] hombres. [El] séptimo artículo de la fe, castigo (....) [o] premio. Este primer artículo de la fe ... [Los] artículos de la fe salvan (?) las almas. [Al] cuerpo [y al] alma [la] gloria espera.

14 Ver Tierra en L. REsines, Diccionario de los catecismo pictográficos, Valladolid, Diputación de Valladolid, 2007, 278. 


\section{PARTE. MANDAMIENTOS DE LA LEY DE DIOS}

Sin solución de continuidad, una vez terminado el formulario de los artículos de la fe, comienza el de los mandamientos. En otros catecismos pictográficos era normal un franja más ancha de separación que una simple línea, ordinariamente adornada, y precedida de un «amén» conclusivo, aunque no se tratara propiamente de una oración, sino de un formulario de la fe. Aquí no aparece nada de eso, en un texto que resulta simple, desprovisto de adornos y florituras.

Si en la primera parte, las escenas estaban marcadas por cada uno de los artículos de la fe, en la segunda son los mandamientos quienes limitan la extensión de cada escena.

\section{Pictograma B77}

Idéntico al pictograma $\mathrm{B} 68$, una mano indicativa (con todos los dedos de la misma longitud) señala a un círculo. Le corresponde, pues, la misma equivalencia: este primer.

\section{Pictograma B78}

Repite el pictograma B75, y el B33. Tiene la misma correspondencia: gloria.

\section{Pictograma B79}

Numeral. Aparecen dos filas verticales de círculos, cada una de las cuales tiene cinco, no están unidos entre sí por una línea, como en otras ocasiones. Su sentido es: diez.

La escena $23^{\mathrm{a}}$, primera de los mandamientos, resulta un poco forzada, además de la dificultad interna, porque no hay un pictograma que exprese la idea de mandamiento, como lo había para artículo de la fe. Simplemente los enumera. El conjunto sería, pues: este primero [para la] gloria [son] diez [mandamientos].

\section{Pictograma B80}

Una fila de tres círculos dispuestos en vertical; el inferior está levemente dañado por un desgarro del papel en el ángulo inferior izquierdo de la hoja, pero se lee perfectamente. Es el numeral: tres. 


\section{Pictograma B81}

89 Igual al B14, dibuja la cabeza divina por su corona. Equivale a:

\section{Pictograma B82}

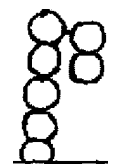

El numeral está representado por una hilera de cinco círculos verticales a la izquierda, más dos en la hilera siguiente, a la que están unidos por una raya. Es evidente su sentido: siete.

\section{Pictograma B83}

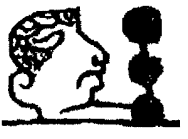

Una cabeza humana, sin corona de divinidad, más un ligero trazo que podría representar la continuación hacia el cuerpo. Este trazo lleva a una hilera de tres círculos dispuestos en vertical a la derecha del pictograma, pero es evidente que forman parte de él; estos tres círculos, unidos entre sí, aparecen dibujados en negro y no vuelve a aparecer ninguna otra vez en el catecismo. Si sólo hubiera aparecido la cabeza humana, no tendría dificultad de interpretación el pictograma (el hombre, o también el prójimo). Pero esta hilera de tres círculos negros dificulta la interpretación: [para el] hombre ¿[y] tres [beneficios]? (o simplemente [para el] hombre [y su] beneficio?).

Es la escena $24^{\mathrm{a}}$, que quedaría, con una cierta soltura: tres [para] Dios, siete [para el] hombre [y su] beneficio.

\section{Pictograma B84}

Un círculo representa el ordinal: [el] primero.

\section{Pictograma B85}

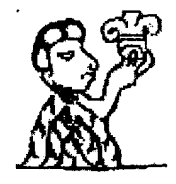

La figura divina, como aparece en el pictograma B28, con la diferencia de que en lugar del globo de la tierra, tiene en su mano una figura geométrica. Ésta se puede describir como la que aparece en B49 y B76, pero en posición invertida. El sentido del dibujo, marcado por el texto del formulario, no ofrece discusión: [a] Dios amar.

La breve escena $25^{\mathrm{a}}$ es así: [el] primero [a] Dios amar. 


\section{Pictograma B86}

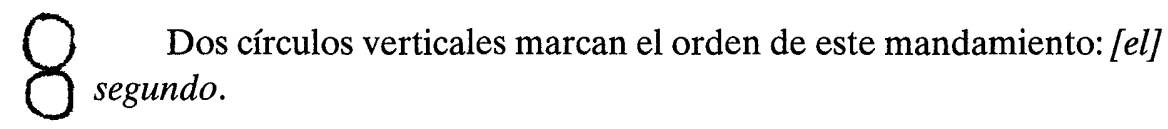

\section{Pictograma B87 y B88}

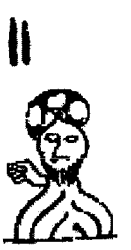

La figura divina de frente, como en B10, tiende su mano derecha hacia dos pequeñas rayas verticales situada junto a él, exactamente debajo del numeral del pictograma anterior. Me ha parecido más oportuno marcarlos como pictogramas diversos, por el hecho de que no están totalmente unidos (como ocurre en B28, B85 o más adelante, en B93). La equivalencia hay que deducirla por el contexto literario, más que por la representación plástica: [el] nombre (?) [de] Dios [honrar?] (o, acaso, [a] Dios honrar).

La escena completa, la 26a , breve, sería: [el] segundo, [a] Dios honrar.

\section{Pictograma B89}

\}

Tres círculos aparecen en columna vertical a la izquierda de la escena, representando al ordinal: [el] tercero.

\section{Pictograma B90}

Extraño pictograma, que no tiene correspondencia con ninguno de los que conozco: un rectángulo alargado y estrecho, algo más ancho por la parte superior, está en posición vertical; en su parte inferior, apuntando hacia abajo, aparece la punta de una lanza (o flecha). No tiene fácil equivalencia; sólo es posible deducir una interpretación, pues se trata el tercer mandamiento, conocido: ir o acudir, en función del desciframiento del pictograma siguiente.

\section{Pictograma B91}

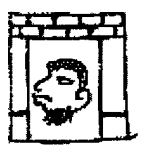

Muy parecido al pictograma B65, allí tenía la equivalencia de castigo. Aquí no cuadra. Además hay algunas diferencias: el edificio sólo tiene sillares o ladrillos por la parte superior (dos hileras), mientras que a los lados unas jambas o postes la sostienen; la persona que hay en su interior está representada sólo por la cabeza (en B65 eran la cabeza y el cuerpo), y no tiene a su lado el óvalo (¿maíz?) que aparecía en aquella ocasión. No tiene lógica acudir al significado de castigo para situarlo en el tercer man- 
damiento. Pero otros catecismos pictográficos, para hablar de esta misma obligación, emplean el dibujo de una construcción (adornada) que representa la iglesia, el templo (G13, Mu 144, M69...), o sólo la puerta del mismo (S173). En este enmarque, tiene sentido descifrarlo como: [a la] iglesia.

Toda la escena $27^{a}$ se entendería, pues, como; [el] tercero, acudir [a la] iglesia.

El tlacuilo cometió aquí un segundo error por omisión, puesto que no marcó la línea vertical de separación entre esta escena, y la que sigue, que se refiere, evidentemente, al mandamiento cuarto. Ya le había sucedido lo mismo entre las escenas $6^{\mathrm{a}}$ y $7^{\mathrm{a}}$.

\section{Pictograma B92}

8 Cuatro círculos dispuestos en vertical son el ordinal corres-

\section{Pictograma B93}

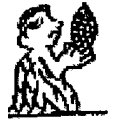

Una persona, de perfil, sostiene en sus manos un óvalo cuajado de pequeños círculos. Es idéntico al pictograma B67, al que asigné el significado de premio. En esa misma línea, aquí podría adquirir el matiz afín de premiar o el de dar (como equivalente a atender).

\section{Pictograma B94}

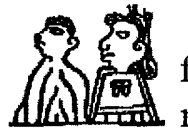

Entiendo que es un solo pictograma, si bien compuesto por dos figuras, unidas entre sí. La primera es la de una persona, sin ningún rasgo distintivo; la segunda es con evidencia una mujer: cabello largo, tocado o adorno en el mismo, vestido hasta los pies (todos aparecen así salvo las figuras desnudas) pero rectilíneo, con un adorno en el pecho, y cinco pequeños cuadrados en el borde mismo de la ropa.Podría representar al hombre y a la mujer (saldrá luego este segundo sentido); pero es notorio que, para ajustarse al cuarto mandamiento, su significado propio en este momento es: padre [y] madre.

Es la escena $28^{\mathrm{a}}$, que muestra el cuarto mandamiento: [el] cuarto, atender [al] padre [y a la] madre.

\section{Pictograma B95}

8 La cadena vertical de cinco círculos representa al ordinal: [el] quinto. 


\section{Pictograma B96}

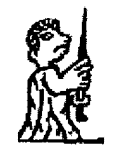

Una figura humana sostiene en sus manos, por la hoja, una espada, con la empuñadura hacia abajo y la punta hacia arriba. Es similar a B61, pero quien sostenía allí la espada era divino, era Jesús, juez. Aquí es un hombre que, con la espada, podría matar a otro. Equivale a: matar.

\section{Pictograma B97}

Otro personaje aparece casi completo (le falta, por rotura, una parte de la ropa). Su mano tendida hacia la persona del pictograma anterior parece denotar una actitud negativa, de rechazo, que se corrobora en los pictogramas de los mandamientos que siguen, que disponen de formulación negativa. El pictograma podría decir: no querer.

La escena completa, 29a , diría de esta forma: [el] quinto, matar no querer.

Pictograma B98 (suplido por B060)

$8 \begin{aligned} & \text { Desaparecido por rotura del papel, tendría que figurar una co- } \\ & 8 \text { lumna de seis círculos que representaran el ordinal: [el sexto]. }\end{aligned}$

Pictograma B99 (suplido por B097)

También ha desaparecido el pictograma que, lógicamente, debería ser un personaje igual al del B97en actitud de rechazo. (Sólo se llega a ver un poco del vestido en la parte inferior, y un vestigio de la mano). La equivalencia sería la misma: [no querer].

\section{Pictograma B100}

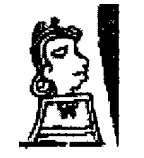

Hay dibujada una mujer igual a la que figuraba en el pictograma B94; pero está sola. Su sentido primero sería: mujer, y no madre, como correspondía a B94. La formulación del mandamiento propone a la mujer como objeto (o sujeto) de pecado, o como elemento emblemático del pecado de impureza. Por lo cual, el sentido que le correspondería, acorde con el formulario de los mandamientos sería:fornicar, cometer impureza.

La escena, casi reconstruida en su totalidad, quedaría como: [el sexto], [no querer] fornicar. 


\section{Pictograma B101}

88

Dos columnas de círculos, cinco en la primera y dos en la segunda, unidas, señalan el orden: [el] séptimo.

\section{Pictograma B102}

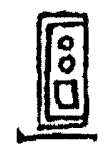

Alojado en el pequeño espacio que hay en la columna de los dos círculos del pictograma anterior, aparece un rectángulo alargado, remarcado, en cuyo interior hay dibujados dos circulitos y un pequeño rectángulo. Podría tratarse de la superficie de una mesa, sobre la cual hay monedas. En cualquier caso, lo que el pictograma trata de expresar es que se trata del objeto del séptimo mandamiento: [los] bienes.

\section{Pictograma B103}

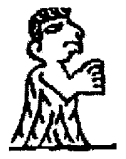

Es el dibujo de una persona que llega a tocar con su mano extendida el pictograma anterior, dando a entender sintonía, o mejor aún, propiedad en este caso particular. Podría entenderse el significado como: de alguien, de otro.

Se completa la escena $31^{a}$, que podría entenderse así: [el] séptimo, [los] bienes de alguien [respetar].

\section{Pictograma B104}

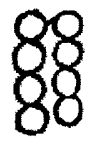

Dos columnas enlazadas de cuatro círculos cada una dan la imagen de ordinal: [el] octavo.

\section{Pictograma B105}

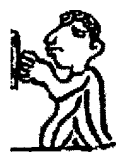

Una figura, igual a la de B97, significaría: no querer.

\section{Pictograma B106}

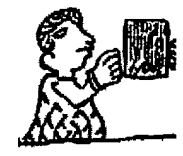

Otra figura semejante a la del pictograma anterior. Entre los dos personajes, hay un cuadrado con líneas en su interior; bien pudiera ser una representación de una comunicación escrita, sirviéndose precisamente de la escritura pictográfica. Ambos personajes lo están tocando, como algo que les une a los dos. He optado por el criterio 
de unir tal cuadrado al personaje segundo, el de este pictograma, para poder encajar mejor el sentido que el pictograma adquiere, que, acorde con la formulación de los mandamientos, sería: [la] mentira [a] alguien.

La escena $31^{\mathrm{a}}$, que corresponde al siguiente mandamiento sería, en consecuencia: [el] octavo, no querer [la] mentira a alguien.

\section{Pictograma B107}

88 Dos columnas de círculos; la de la derecha tiene cinco, y, unida a ella, la de la izquierda sólo acoge cuatro: [el] noveno.

\section{Pictograma B108}

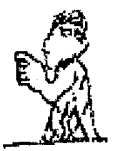

La misma figura de B97, la supuesta de B99, o de B105 extiende su mano, sin llegar a tocar lo que aparece dibujado en el pictograma siguiente. Como el formulario de los mandamientos reserva estos dos últimos para prohibir los pecados de intención, de deseo, parece más adecuado desplazar el significado a: no desear.

\section{Pictograma B109}

Igual a B100, representa la mujer, objeto de deseos libidinosos, que son prohibidos por el mandamiento. Aparece solamente la mujer, sin que sea acompañada por otro pictograma que supusiera la idea de otro, o la de ajena. Hay que darlo por descontado. El sentido es, por tanto: [la] mujer.

Y la escena $33^{\mathrm{a}}$, completa, arroja este resultado: [el] noveno, no desear [la] mujer.

\section{Pictograma B110}

Dos columnas de círculos, que en esta ocasión no están unidas entre sí por un trazo, como suele ser habitual. No obstante el sentido es claro: [el] décimo.

\section{Pictograma B111}

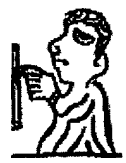

Personaje que es repetición de B105 y B108. En lógica correspondencia con este último pictograma, por lo que supone de evitar los pecados de intención, su equivalencia es: no desear. 


\section{Pictograma B112}

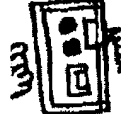

Se repite, en tamaño un poco más grande, el pictograma B102, que representaba los bienes en el séptimo mandamiento. Obviamente, su sentido es el mismo: [los] bienes.

\section{Pictograma B113}

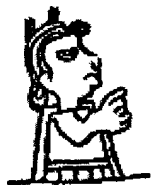

Igual a los pictogramas B100 y B109, es la representación de la mujer.

La escena $34^{\mathrm{a}}$, que incluye los cuatro últimos pictogramas, tiene el sentido siguiente: [el] décimo, no desear [los] bienes [ni la] mujer. Se sobreentiende, como ocurría en el noveno mandamiento, que se trata de la mujer de otro. Hay, con todo, una situación un tanto anómala, porque si el noveno mandamiento se refería a la prohibición de deseos hacia la mujer ajena, parece poco lógico volver a repetir este mismo extremo en la expresión para el décimo mandamiento. Pero ahí están los pictogramas que así lo presentan. $Y$ contra esto no vale discusión alguna.

\section{Pictograma B114}

Dos columnas de cinco círculos cada una muestra el numeral que incluye la cifra total de los mandamientos: diez.

\section{Pictograma B115}

Unido al pictograma anterior con una raya, pero conceptualla indicación que la raya supone en otras ocasiones (B3, B4, B6...), en este pictograma aparecen dos círculos. Representan al número: $d o s$.

\section{Pictograma B116}

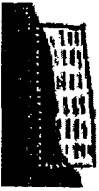

Contra lo que cabría esperar, y a pesar de que indiqué en la descripción de B71 que aparecía por última vez, vuelve a aparecer aquí el rectángulo rayado habitual en la primera parte del manuscrito. Está deteriorado por el roto de la parte inferior izquierda, pero es perfectamente reconocible. En esa primera parte, tenía el sentido de artículo de la fe, a que se refería el catecismo. Precisamente por eso señalé que se trataba de la última aparición. Pero ahora no le cuadra ese sentido; muy al contrario, hay que entenderlo con otro giro, porque es evidente que 
en esta segunda parte está hablando de los mandamientos, sentido que aquí encaja a la perfección.

La escena $35^{\text {a }}$ comienza la sentencia conclusiva de los mandamientos, como síntesis de ellos: [los] diez [en] dos mandamientos.

Pictograma B117 (suplido por el B011)

El desgarro del papel en este ángulo hace que falten, razonablemente, dos pictogramas que hay que suponer. Uno hay que imaginarlo por la lógica que muestra en seguida el pictograma B120, que significa segundo: no puede haber segundo sin primero. Por tanto el pictograma perdido tiene que ser el de un círculo con el sentido de: [el primero].

Pictograma B118 (suplido por el B005)

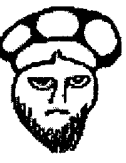

El otro pictograma desaparecido ha de ser el que corresponde a la imagen de Dios, que podría corresponder sólo al rostro divino (como B5), o a la figura completa (como B10). Se habría de incluir su equivalencia: [a Dios].

\section{Pictograma B119}

๑) Se repite, aunque un poco perdido en un extremo, el pictograma B76, que tenía el significado de esperar. También podría encajar el de amar, por la lógica de la expresión usual. En B85 he señalado el sentido de amar a este pictograma, que está en posición invertida respecto a B76. La fórmula usual inclina la balanza en esta dirección al asignarle su sentido: amar.

La reconstrucción de la escena $36^{\mathrm{a}}$, gravemente deteriorada, pero que resulta fácil reconstruir, es bastante evidente: [el primero] [a Dios] amar.

\section{Pictograma B120}

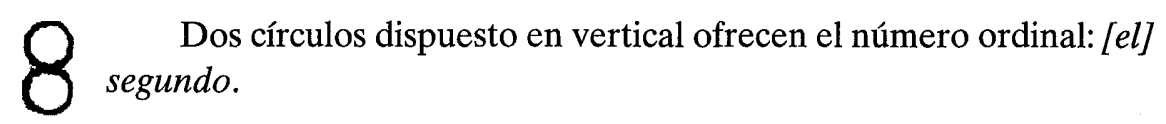

\section{Pictograma B121}

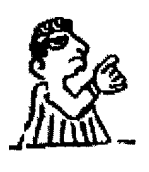

Consta simplemente de un personaje con la mano extendida, como los que aparecen en otras ocasiones (p. ej. B108). El sentido de la frase conclusiva de los mandamientos apuntaría a una equivalencia: prójimo. En el pictograma B83, en la presentación pro- 
gramática de los mandamientos, hice alusión a dos posibles sentidos: hombre, o también prójimo. Aunque B83 sólo presenta la cabeza, acompañada de otro elemento, parece que al descifrarlo en este lugar, hay que retomar el sentido propuesto, dado el texto del formulario de los mandamientos: prójimo.

\section{Pictograma B122}

El personaje del pictograma anterior señala con el índice a este otro personaje, estático, del que no aparecen manos ni ningún otro rasgo especial. Se impone atender a la expresión sintética con que concluye la formulación de los mandamientos para deducir su equivalencia: [a] ti mismo.

.186) La escena $37^{\mathrm{a}}$, última del manuscrito, se condensa en: [el] segundo, [al] prójimo [como a] ti mismo.

El resto de la última banda, como ya he indicado, quedó en blanco, sin utilizar, una vez que el amanuense concluyó la presentación de los mandamientos. Tampoco en esta ocasión aparece un posible «amén», que figura en otros catecismos pictográficos. Es un final brusco, que se entiende mejor si se asume la posibilidad de que este manuscrito, junto con otros, de tamaño aproximado, figurara en las paredes del templo.

El desciframiento total de la segunda parte, reuniendo la explicación de todas las sucesivas escenas en que dividió el amanuense los mandamientos, arroja este resultado:

Este [o quizá lo] primero [para la] gloria [son] diez [mandamientos]: tres [para] Dios, siete [para el] hombre [y su] beneficio. [El] primero, [a] Dios amar. [El] segundo, [a] Dios honrar. [El] tercero, acudir [a la] iglesia. [El] cuarto, atender [al] padre [y a la] madre. [El] quinto, matar no querer. [El sexto], [no querer] fornicar. [El] séptimo, [los] bienes de alguien [respetar]. [El] octavo, no querer [la] mentira a alguien. [El] noveno, no desear [la] mujer. [El] décimo, no desear [los] bienes [ni la] mujer.

[Los] diez [en] dos mandamientos: [el primero] [a Dios] amar; [el] segundo, [al] prójimo [como a] ti mismo.

La contemplación de estas dos partes o formularios de la fe cristiana reclama una cierta explicación. En principio, parece poco lógico que el amanuense haya reunido en una misma hoja estos dos formularios. Parecería más adecuado que hubieran figurado formularios afines: así, sería más coherente que hubieran aparecido el credo, seguido de los artículos de la fe, como expresión duplicada casi por entero de las afirmaciones dogmáticas de los cristianos. También hubiera entrado en la lógica que hubieran figurado los mandamientos de la ley de 
Dios, y a continuación los mandamientos de la Iglesia. Pero no es así.

Hay, con todo, una razón que avala la presentación de estos dos formularios en el orden preciso en que aparecen en este manuscrito. Los artículos de la fe concluyen con una llamada a Cristo que vendrá como juez, para premiar o castigar a los hombres, según hayan o no cumplido los mandamientos. Es, pues, lógico que a continuación aparezcan los mandamientos que es preciso cumplir para hacerse acreedor al premio prometido y evitar el castigo ${ }^{15}$. Según este razonamiento, el pictograma $\mathrm{B} 71$, al que he asignado el sentido ordinario de artículos de la fe, podría tener igualmente el sentido de mandamientos, como aparece también en B116. Los artículos de la fe no son sólo unos conocimientos teóricos, sino que conducen a un comportamiento práctico, que está reglado en los mandamientos expuestos a continuación. De esta forma, el manuscrito tiene sentido en sí mismo, aunque no incluya todos los formularios habituales en los catecismos elementales, o cartillas de la doctrina cristiana, como eran estos pictográficos.

LUIS RESINES LLORENTE

${ }^{15}$ La formulación más difundida en el XVI del artículo último relativo a la humanidad de Cristo, era así: «creer que vendrá a juzgar a los vivos y a los muertos, conviene a saber, a los buenos para darles gloria, porque guardaron sus santos mandamientos, y a los malos pena perdurable porque no los guardaron». Los últimos pictogramas, como se ve, giran en torno a estas ideas, aunque no haya dado con una correspondencia exacta. 


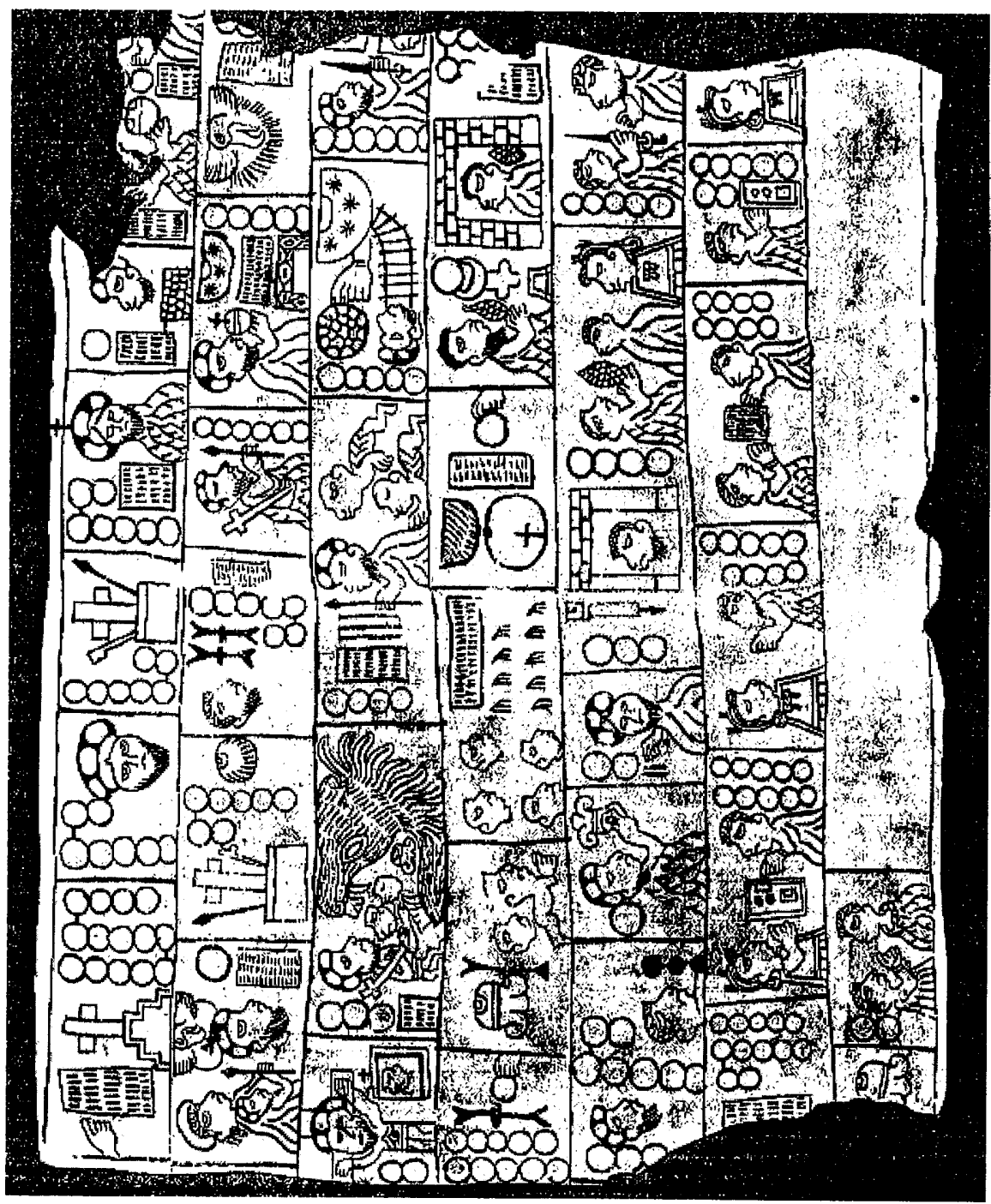

